\title{
Association of the leptin gene with knee osteoarthritis susceptibility in a Han Chinese population: a case-control study
}

\author{
Jianghui Qin ${ }^{1,2,4}$, Dongquan Shi ${ }^{1,2,4}$, Jin Dai ${ }^{1,2}$, Lunqing Zhu ${ }^{1}$, Aspasia Tsezou ${ }^{3}$ and Qing Jiang ${ }^{1,2}$
}

Previous studies have suggested that leptin works as a key regulator in the pathogenesis of osteoarthritis (OA), and genetic factors modulate OA. This study assessed the contribution of leptin gene (LEP) polymorphism(s) to knee OA among Han Chinese. Three tag single-nucleotide polymorphisms (SNPs) covering all those LEP SNPs of which the minor allele frequencies were over $10 \%$ were selected. Study subjects (697 patients and 699 controls) were divided into four groups (underweight, normal weight, overweight and obese) by body mass index (BMI). Allele and genotype frequencies in the three tag SNPs were significantly different in the normal weight and overweight groups. In the normal weight, overweight and obese groups, BMI $\left(P=4.3 \times 10^{-5}, 0.012\right.$ and 0.009 , respectively) and gender $\left(P=3.5 \times 10^{-22}, 5.1 \times 10^{-23}\right.$ and $2.1 \times 10^{-8}$, respectively) were effective factors. Age was an independent effective factor in the overweight group $(P=0.009)$. Haplotypes were associated with $O A$ in the normal weight group (CAT, $P=0.015$ ) and the overweight group (AGC, $P=0.015$ ). Our results suggest an association between $L E P$ and knee $O A$ in the normal weight and overweight groups among Han Chinese.

Journal of Human Genetics (2010) 55, 704-706; doi:10.1038/jhg.2010.86; published online 22 July 2010

Keywords: case-control association study; leptin; osteoarthritis; tag SNPs

\section{INTRODUCTION}

Knee osteoarthritis (OA) usually causes considerable pain and frequent instability, consequently resulting in physical disability. ${ }^{1}$ Among Chinese of over 60 years of age, prevalence of symptomatic knee OA is $19.4 \% .^{2}$ For knee OA, obesity is a major risk factor, and genetic factors modulate obesity and OA. ${ }^{3}$ Classic twin studies have shown that the genetic influence is between 39 and $65 \%$ in radiographic $\mathrm{OA}$ of the hand and knee in women. ${ }^{4}$ Previous studies found associations of knee OA with ASPN, GDF5 and DVWA, and metaanalysis showed global association in GDF5, whereas ASPN and DVWA have ethnic differences. ${ }^{5-7}$

Leptin is a $16-\mathrm{kDa}$ non-glycosylated peptide hormone, mainly produced by adipocytes. ${ }^{8}$ Leptin protein level is much higher in OA cartilage than in normal cartilage. ${ }^{9}$ It participated in the pathogenesis of OA by affecting chondrocyte metabolism. ${ }^{10,11} \mathrm{~A}$ high level of leptin expression increases nitric oxide, matrix metaloprotease- 9 and matrix metaloprotease- 13 expression, affects chondrocyte function and finally results in OA. ${ }^{11,12}$ However, so far, few studies have been conducted on the possible existence of association between leptin gene (LEP) polymorphisms and OA susceptibility.
This study was conducted to investigate the association between $L E P$ and knee $\mathrm{OA}$ in the Han Chinese population.

\section{PATIENTS AND METHODS}

A total of 697 knee OA patients (528 females and 169 males) and 699 healthy control subjects (288 females and 411 males) were studied. All subjects were Han Chinese living in and around Nanjing and were over 40 years of age. The criterion for inclusion and exclusion of knee OA patients was the same as that of the previous study. ${ }^{13}$ For all subjects, body mass index (BMI) was calculated to assess obesity. Patients with a KellgrenLawrence $(\mathrm{K}-\mathrm{L})$ score $^{14}<2$ were excluded. Control subjects never had any signs or symptoms of arthritis or joint diseases. The study was approved by the ethics committee of the Medical School of Nanjing University, and informed consent was obtained from patients and controls before they attended this study.

Three tag single-nucleotide polymorphisms (SNPs) of LEP (rs11761556, rs12706832, rs2071045) were selected by Haploviewer software (http://www. hapmap.org) from the Hapmap database. They covered all the SNPs, the minor allele frequencies of which were over $10 \%$, at $r^{2}$ not $<0.8$. Genomic DNA was extracted from peripheral blood leukocytes using the Chelex-100 method ${ }^{15}$ or from buccal swabs using the DNA IQ System (Promega, Madison, WI, USA).

\footnotetext{
${ }^{1}$ The Center of Diagnosis and Treatment for Joint Disease, Department of Orthopaedic Surgery, Drum Tower Hospital Affiliated to Medical School of Nanjing University, Nanjing, Jiangsu, China; ${ }^{2}$ Laboratory for Bone and Joint Diseases, Model Animal Research Center, Nanjing University, Nanjing, Jiangsu, China and ${ }^{3}$ Department of Biology, Medical School, University of Thessaly, Larissa, Greece

${ }^{4}$ These authors contributed equally to this work.

Correspondence: Dr A Tsezou, Department of Biology, Medical School, University of Thessaly, Larissa, Greece.

E-mail: atsezou@med.uth.gr or Dr Q Jiang, The Center of Diagnosis and Treatment for Joint Disease, Drum Tower Hospital Affiliated to Medical School of Nanjing University, Zhongshan Road 321, Nanjing 210008, Jiangsu, China.

E-mail: qingj@nju.edu.cn
}

Received 3 May 2010; accepted 5 June 2010; published online 22 July 2010 
Table 1 Information on the four groups divided by BMI

\begin{tabular}{|c|c|c|c|c|c|c|c|c|c|c|}
\hline \multirow[b]{2}{*}{ Group } & \multicolumn{2}{|c|}{ Whole } & \multicolumn{2}{|c|}{ Underweight } & \multicolumn{2}{|c|}{ Normal weight } & \multicolumn{2}{|c|}{ Overweight } & \multicolumn{2}{|c|}{ Obese } \\
\hline & $O A$ & Control & $O A$ & Control & $O A$ & Control & $O A$ & Control & $O A$ & Control \\
\hline Number & 697 & 699 & 9 & 84 & 328 & 358 & 291 & 187 & 69 & 70 \\
\hline Age $^{a}$ & $59.6 \pm 9.9$ & $58.5 \pm 10.5$ & $55.8 \pm 11.9$ & $62.2 \pm 13.5$ & $59.5 \pm 9.9$ & $58.8 \pm 10.3$ & $60.0 \pm 9.8$ & $58.0 \pm 9.3$ & $59.1 \pm 10.2$ & $55.8 \pm 10.5$ \\
\hline $\mathrm{BMI}^{\mathrm{b}}$ & $25.4 \pm 3.4$ & $23.9 \pm 4.9$ & $17.5 \pm 1.0$ & $17.3 \pm 1.0$ & $22.8 \pm 1.6$ & $22.5 \pm 1.7$ & $27.1 \pm 1.4$ & $26.8 \pm 1.3$ & $32.1 \pm 1.8$ & $33.5 \pm 3.3$ \\
\hline
\end{tabular}

Abbreviations: BMI, body mass ratio; OA, osteoarthritis.

Whole, all subjects; underweight, $\mathrm{BMI}<18.5$; normal, $18.5 \leqslant \mathrm{BMI}<25$; overweight, $25 \leqslant \mathrm{BMI}<30$; obese, $\mathrm{BMI} \geqslant 30$.

a Year (mean \pm s.d.).

${ }^{b} \mathrm{Kgm}^{-2}$ (mean \pm s.d.)

SNPs were genotyped using TaqMan SNP genotyping assays (Applied Biosystems, Foster City, CA, USA). Standard $\chi^{2}$-analysis-of-contingency tables were used to compare genotypes of the three tag SNPs and allele distributions. HardyWeinberg equilibrium was determined by $\chi^{2}$-test. A logistic regression analysis was carried out to identify risk factors in each group. Haplotype association was analyzed using SHEsis software. ${ }^{16}$

\section{RESULTS}

There was no difference in the mean age between case and control groups (Table 1). There were statistical differences in the mean BMI $\left(P=2.45 \times 10^{-8}\right.$; Table 1$)$ and sex distributions $\left(P=3.78 \times 10^{-39}\right)$ between case and control groups. Over $50.8 \%$ of patients had a $\mathrm{K}-\mathrm{L}$ score of 3 or 4 . The $\mathrm{K}-\mathrm{L}$ score was correlated with age $\left(P=4.23 \times 10^{-33}\right.$, correlation coefficient $\left.=0.432\right)$ and BMI $(P=0.04$, correlation coefficient $=0.108$ ).

To avoid the possible confounding from body weight, subjects were separated into four groups by the World Health Organization international classification according to BMI (Table 1). Statistical analysis was not performed in the underweight group, as the subject number was insufficient. Distributions of genotypes in control groups were conformed to Hardy-Weinberg equilibrium.

\section{The normal weight group}

Significant differences were observed with regard to the allele and genotype frequencies of the three SNPs (Table 2). BMI $\left(P=4.32 \times 10^{-5}\right)$ and gender $\left(P=3.50 \times 10^{-22}\right)$ were both found to be risk factors for knee OA by logistic regression analysis.

\section{The overweight group}

Significant differences were observed with regard to the allele and genotype frequencies of the three SNPs (Table 2). Age $(P=0.009)$, gender $\left(P=5.09 \times 10^{-23}\right)$ and BMI $(P=0.012)$ were found to be risk factors for knee OA by logistic regression analysis.

\section{The obese group}

No significant difference in allelic and genotype frequency distribution was observed. Gender $\left(P=2.13 \times 10^{-8}\right)$ and BMI $(P=0.009)$ were found to be risk factors for knee $\mathrm{OA}$ by logistic regression analysis.

\section{Haplotype analysis}

The sequences of loci selected for haplotype analysis were rs11761556, rs12706832 and rs2071045. Haplotypes with a frequency of $<3 \%$ were ignored. Haplotype frequencies (Supplemental Table 1) were significantly different between case and control subjects in the normal weight group (AGC and CAT) and in the overweight group (AGC and CGC). No significant difference was observed in the obese group.
Table 2 Association of the three SNPs for the three groups

\begin{tabular}{|c|c|c|c|c|c|}
\hline Group & SNP & Comparison & P-value & Odds ratio & $95 \% \mathrm{Cl}$ \\
\hline \multirow[t]{9}{*}{ Normal } & \multirow[t]{3}{*}{ rs11761556 } & CC vs others & 0.674 & 0.90 & $0.53-1.50$ \\
\hline & & AA vs others & 0.005 & 0.65 & $0.48-0.88$ \\
\hline & & $\mathrm{C}$ allele vs $\mathrm{A}$ allele & 0.016 & 1.34 & $1.06-1.70$ \\
\hline & \multirow[t]{3}{*}{ rs12706832 } & GG vs others & 0.002 & 1.61 & $1.19-2.19$ \\
\hline & & $A A$ vs others & 0.898 & 0.96 & $0.51-1.80$ \\
\hline & & G allele vs $A$ allele & 0.014 & 0.73 & $0.57-0.94$ \\
\hline & \multirow[t]{3}{*}{ rs2071045 } & TT vs others & 0.272 & 0.81 & $0.56-1.18$ \\
\hline & & CC vs others & 0.024 & 0.69 & $0.50-0.95$ \\
\hline & & T allele vs $C$ allele & 0.034 & 1.26 & $1.02-1.56$ \\
\hline \multirow[t]{9}{*}{ Overweight } & \multirow[t]{3}{*}{ rs11761556 } & CC vs others & 0.223 & 1.57 & $0.76-3.26$ \\
\hline & & AA vs others & 0.007 & 1.66 & $1.15-2.41$ \\
\hline & & $\mathrm{C}$ allele vs $\mathrm{A}$ allele & 0.009 & 0.68 & $0.50-0.91$ \\
\hline & \multirow[t]{3}{*}{ rs12706832 } & GG vs others & 0.267 & 0.81 & $0.56-1.17$ \\
\hline & & AA vs others & 0.048 & 0.41 & $0.16-1.02$ \\
\hline & & G allele vs $A$ allele & 0.100 & 1.29 & $0.95-1.74$ \\
\hline & \multirow[t]{3}{*}{ rs2071045 } & TT vs others & 0.047 & 1.63 & $1.00-2.66$ \\
\hline & & $\mathrm{CC}$ vs others & 0.694 & 1.08 & $0.73-1.60$ \\
\hline & & T allele vs $\mathrm{C}$ allele & 0.166 & 0.83 & $0.64-1.08$ \\
\hline \multirow[t]{9}{*}{ Obese } & \multirow[t]{3}{*}{ rs11761556 } & CC vs others & 0.998 & 1.01 & $0.14-7.42$ \\
\hline & & $A A$ vs others & 0.556 & 1.23 & $0.62-2.41$ \\
\hline & & $\mathrm{C}$ allele vs $\mathrm{A}$ allele & 0.618 & 0.87 & $0.49-1.53$ \\
\hline & \multirow[t]{3}{*}{ rs12706832 } & GG vs others & 0.266 & 0.68 & $0.34-1.35$ \\
\hline & & AA vs others & 0.637 & 0.65 & $0.10-4.00$ \\
\hline & & G allele vs $A$ allele & 0.276 & 1.38 & $0.77-2.46$ \\
\hline & \multirow[t]{3}{*}{ rs2071045 } & TT vs others & 0.693 & 0.84 & $0.36-1.98$ \\
\hline & & CC vs others & 0.081 & 1.89 & $0.92-3.88$ \\
\hline & & T allele vs $C$ allele & 0.341 & 0.79 & $0.49-1.28$ \\
\hline
\end{tabular}

Abbreviations: $\mathrm{Cl}$, confidence interval; SNP, single-nucleotide polymorphism.

\section{DISCUSSION}

Mean BMI and sex distribution were significantly different between case and control subjects. This is coincident with the previous conclusion that obesity and gender are major risk factors for knee OA. ${ }^{17}$ Our results showed that age was an independent risk factor in the overweight group. In this group, the frequency distribution of two genotypes (AA at rs12706832 and TT at rs2071045) was different. It is almost similar to a false-positive association, as $P$-values were slightly below the threshold (0.05), and there was no trend of difference in distribution in the normal weight and obese groups.

Notably, the results of our study showed LEP polymorphisms as a risk factor in the normal weight and overweight groups, but not in the obese group. It may be due to the limited number of subjects. Another possibility is that significantly high BMI covered up the influences of 
LEP polymorphisms and age, rendering them not so important in the process of knee OA.

This is the first report that detected an association between $L E P$ and knee OA. Our results indicated that in normal weight and overweight Han Chinese, LEP polymorphisms, sex and BMI were associated with knee OA. Age was an independent risk factor for knee OA in the overweight population. Sex and BMI were risk factors for knee OA in the obese population.

\section{CONFLICT OF INTEREST}

The authors declare no conict of interest.

1 Fitzgerald, G. K., Piva, S. R. \& Irrgang, J. J. Reports of joint instability in knee osteoarthritis: its prevalence and relationship to physical function. Arthritis Rheum. 51, 941-946 (2004).

2 Xiang, Y. J. \& Dai, S. M. Prevalence of rheumatic diseases and disability in China. Rheumatol. Int. 29, 481-490 (2009).

3 Manek, N. J., Hart, D., Spector, T. D. \& MacGregor, A. J. The association of body mass index and osteoarthritis of the knee joint: an examination of genetic and environmental influences. Arthritis Rheum. 48, 1024-1029 (2003).

4 Spector, T. D., Cicuttini, F., Baker, J., Loughlin, J. \& Hart, D. Genetic influences on osteoarthritis in women: a twin study. BMJ 312, 940-943 (1996).

5 Nakamura, T., Shi, D., Tzetis, M., Rodriguez-Lopez, J., Miyamoto, Y., Tsezou, A. et al. Meta-analysis of association between the ASPN D-repeat and osteoarthritis. Hum. Mol. Genet. 16, 1676-1681 (2007).

6 Chapman, K., Takahashi, A., Meulenbelt, I., Watson, C., Rodriguez-Lopez, J., Egli, R. et al. A meta-analysis of European and Asian cohorts reveals a global role of a functional
SNP in the $5^{\prime}$ UTR of GDF5 with osteoarthritis susceptibility. Hum. Mol. Genet. 17, 1497-1504 (2008).

7 Meulenbelt, I., Chapman, K. Dieguez-Gonzalez, R., Shi, D., Tsezou, A., Dai, J. et al. Large replication study and meta-analyses of DVWA as an osteoarthritis susceptibility locus in European and Asian populations. Hum. Mol. Genet. 18, 1518-1523 (2009).

8 Zhang, Y., Proenca, R., Maffei, M., Barone, M., Leopold, L. \& Friedman, J. M. Positional cloning of the mouse obese gene and its human homologue. Nature 372, 425-432 (1994).

9 Teichtahl, A. J., Wluka, A. E., Proietto, J. \& Cicuttini, F. M. Obesity and the female sex, risk factors for knee osteoarthritis that may be attributable to systemic or local leptin biosynthesis and its cellular effects. Med. Hypotheses 65, 312-315 (2005).

10 Karsenty, G. Convergence between bone and energy homeostases: leptin regulation of bone mass. Cell Metab. 4, 341-348 (2006).

11 Simopoulou, T., Malizos, K. N., Iliopoulos, D., Stefanou, N., Papatheodorou, L., Ioannou, M. et al. Differential expression of leptin and leptin's receptor isoform (Ob$\mathrm{Rb}) \mathrm{mRNA}$ between advanced and minimally affected osteoarthritic cartilage; effect on cartilage metabolism. Osteoarthritis Cartilage 15, 872-883 (2007).

12 Iliopoulos, D., Malizos, K. N. \& Tsezou, A. Epigenetic regulation of leptin affects MMP13 expression in osteoarthritic chondrocytes: possible molecular target for osteoarthritis therapeutic intervention. Ann. Rheum. Dis. 66, 1616-1621 (2007).

13 Jiang, Q., Shi, D., Yi, L., Ikegawa, S., Wang, Y., Nakamura, T. et al. Replication of the association of the aspartic acid repeat polymorphism in the asporin gene with knee-osteoarthritis susceptibility in Han Chinese. J. Hum. Genet. 51, 1068-1072 (2006).

14 Kellgren, J. H. \& Lawrence, J. S. Radiological assessment of osteo-arthrosis. Ann. Rheum. Dis. 16, 494-502 (1957).

15 Walsh, P. S., Metzger, D. A. \& Higuchi, R. Chelex 100 as a medium for simple extraction of DNA for PCR-based typing from forensic material. Biotechniques 10, 506-513 (1991).

16 Shi, Y. Y. \& He, L. SHEsis, a powerful software platform for analyses of linkage disequilibrium, haplotype construction, and genetic association at polymorphism loci. Cell Res. 15, 97-98 (2005).

17 Das, S. K. \& Farooqi, A. Osteoarthritis. Best Pract. Res. Clin. Rheumatol. 22, 657-675 (2008).

Supplementary Information accompanies the paper on Journal of Human Genetics website (http://www.nature.com/jhg) 